\title{
Pengaruh Pengungkapan Sustainability Reporting terhadap Keuangan Perusahaan di Indonesia
}

\author{
Intan Ayu Permata Sari ${ }^{1}{ }^{*}$, Hans Hananto Andreas ${ }^{2}$
}

1,2Fakultas Ekonomi dan Bisnis, Universitas Kristen Satya Wacana, Indonesia

\section{A R T I C L E I N F O}

\section{Article history:}

Received 19 May 2019

Received in revised form

16 June 2019

Accepted 15 July 2019

Available online 26 August 2019

Kata Kunci:

Sustainability Reporting

Kinerja Ekonomi, Kinerja

Lingkungan, Kinerja Sosial,

Kinerja Keuangan

Keywords:

Sustainability Reporting,

Economic Performance,

Environmental

Performance, Social

Performance, Financial

Performance

\section{A B S T R A K}

Tujuan dari penelitian ini adalah untuk mengetahui pengaruh sustainability reporting aspek ekonomi, lingkungan, dan sosial terhadap kinerja keuangan perusahaan manufaktur dan Jasa. Objek dari penelitian ini adalah perusahaan manufaktur dan jasa yang terdaftar di BEl pada tahun 2014-2016. Teknik analisis yang digunakan adalah regresi linear berganda. Hasil penelitian yang diperoleh adalah secara parsial semua dimensi sustainability reporting yaitu kinerja ekonomi, kinerja lingkungan, dan kinerja sosial tidak berpengaruh terhadap kineja keuangan (ROA).

\section{A B S T R A C T}

The purpose of this research was to know the influence of sustainability reporting aspects of the economic, environmental, and social performance of the company's manufacturing and financial services. The object of this research was a company manufacturing and services registered in BEI at 2014-2016. Analytical techniques used multiple linear regressions. The results were partial in all dimensions of sustainability reporting, namely economic performance, environmental performance, social performance and no effect on the financial performance (ROA).

\footnotetext{
* Corresponding author.

E-mail addresses: intanayupermata.ip@gmail.com (Intan Ayu Permata Sari)
} 


\section{Pendahuluan}

Sustainability reporting bagi perusahaan berguna untuk mempublikasikan informasi yang mencerminkan kinerja organisasi dalam dimensi ekonomi, sosial dan lingkungan (ACCA, 2013). Pada masa globalisasi yang terjadi di masa kini, stakeholder tidak hanya melihat kinerja perusahaan dari kinerja keuangan (Eduardus dan Juniarti, 2016). Stakeholder juga melihat dari sisi kinerja non keuangan misalnya lingkungan dan sosial. Kejadian sosial dan lingkungan yang terjadi pada beberapa perusahaan saat ini juga menjadi pemicu dari tuntunan stakeholder (Sari dan Marsono, 2013). Contohnya kasus banjir lumpur panas yang disebabkan oleh perusahaan minyak dan gas, Lapindo Brantas Inc (Sari dan Marsono, 2013).

Pemaparan laporan berkelanjutan (Sustainability Reporting) semakin berkembang. Sustainability reporting juga dipahami dapat memberikan jawaban permintaan stakeholders terhadap kinerja perusahaan dan kinerja manajemen (Ballout et al., 2006 dalam Wijayanti 2016). Stakeholders perusahanan terdiri dari pemegang saham, pemerintah, pelanggan, karyawan, dan masyarakat umum.

Di Indonesia sendiri sustainability reporting diatur oleh Undang-Undang No. 40 tahun 2007 mengenai Personalan Terbatas Pasal 74 menjelaskan bahwa perseorangan yang kegiatan usahanya di bidang dan atau berkaitan dengan sumber daya alam wajib melaksanakan tanggung jawab sosial dan lingkungan (Lesmana dan Tarigan, 2014). Badan pengawas pasar modal dan lembaga keuangan juga mengeluarkan peraturan yang sejenis pada peraturan Nomor X.K.6. Hal ini, dapat dikatakan bahwa pemerintah menunjukkan keseriusan dan perhatian pemerintah mengenai tanggung jawab sosial dan lingkungan di dunia bisnis. Namun, untuk mengungkapkan tanggung jawab ekonomi, lingkungan, dan sosial masih bersifat sukarela (Sari, Artinah, dan Safriansyah, 2017).

Kinerja keuangan perusahaan diartikan sebagai penentu ukuran-ukuran tertentu yang dapat mengukur keberhasilan suatu perusahaan untuk menghasilkan keuntungan (Wijaya dan Sumiati, 2017). Laporan dari kinerja keuangan dibuat untuk menggambarkan keadaan keuangan perusahaan dimasa lampau untuk melihat keadaan keuangan dimasa yang akan datang (Soelistyoningrum dan Prastiwi, 2011). Jika laporan keuangan tersebut dari waktu ke waktu menunjukan hasil yang baik dan konsisten maka dapat dikatakan kondisi kinerja keuangan perusahaan tersebut dinilai baik (Safitri dan Fidiana, 2015). Kinerja keuangan dapat dilihat dari rasio-rasio keuangan yang meliputi manajemen aset, profitabilitas, leverage, likuiditas, dan pasar (Ross et al,. 2013).

Peraturan NCSR (National Center For Sustainability Reporting) mendukung adanya pelaporan berkelanjutan yang semakin berkembang di Indonesia walapun perusahaan di Indonesia tidak semuanya melaporkan sustainability reporting seperti yang dilakukan oleh negara-negara maju. Meningkatnya tren sustainability reporting yang juga diikuti dengan peraturan yang disediakan oleh pemerintah dan industri (Sari dan Marsono, 2013). Salah satu pedoman yang digunakan adalah GRI (Global Reporting Initiative). GRI merupakan organisasi atau lembaga yang berkaitan dengan sustainability reporting. Elkington (1997) pelaporan dalam laporan berkelanjutan dibagi menjadi tiga komponen yaitu, kinerja ekonomi (economic performence), kinerja sosial (social performence), dan kinerja lingkungan (environmental performence).

Fungsi sustainability reporting adalah untuk menginformasikan kinerja ekonomi, sosial, dan lingkungan. Hal ini, sebagai bukti pertanggungjawaban perusahaan dengan stakeholder dan perusahaan berada pada batasan yang ada. Bagi perusahaan perlu untuk melakukan pelaporan sustainability reporting karena kepercayaan stakeholder diperlukan untuk perusahaan sebagai keberlangsungan bisnis bagi perusahaan. Sejati dan Prastiwi (2015) menyatakan bahwa kepercayaan stakeholder dapat berupaya untuk investasi maupun kerjasama yang berpotensi meningkatkan produktivitas dan penjualan perusahaan. Produktivitas dan penjualan perusahaan tersebut dapat mempengaruhi tingkat laba bersih, dimana meningkatnya laba bersih perusahaan akan meningkatkan nilai ROA yang dapat diartikan bahwa kinerja keuangan meningkat.

Bukhori dan Sopia (2017) menunjukkan secara simultan semua dimensi sustainabilty reporting dimensi ekonomi, sosial, dan lingkungan berpengaruh positif signifikan terhadap kinerja keuangan dan secara parsial hanya dimensi sosial yang berpengaruh positif tidak signifikan. Burhan dan Rahmanti (2012) hasil penelitian menunjukkan bahwa kesinambungan pelaporan berpengaruh terhadap kinerja perusahaan, namun hanya pengungkapan kinerja sosial yang berpengaruh positif terhadap kinerja perusahaan saja. Nofianto dan Agustina (2014) berpendapat kinerja ekonomi, kinerja sosial, dan kinerja lingkungan tidak berpengaruh terhadap kinerja keuangan perusahaan. Wijayanti (2016) menunjukan sustainability reporting terhadap kinerja keuangan perusahaan menghasilkan semua dimensi sustainabilty reporting ekonomi, sosial, dan lingkungan berpengaruh positif signifikan dari sisi profitability Return on Asset. Tarigan dan Samuel (2014) menunjukkan bahwa dimensi ekonomi dari sustainability reporting tidak berpengaruh terhadap kinerja keuangan, sedangkan dua dimensi lainnya yaitu lingkungan dan sosial berpengaruh negatif terhadap kinerja keuangan. Adhima (2012) menyatakan bahwa sustainability reporting dan kinerja lingkungan berpengaruh positif signifikan terhadap ROA, sedangkan 
kinerja sosial berpengaruh negatif signifikan terhadap ROA. Secara parsial kinerja ekonomi berpengaruh positif signifikan terhadap kinerja keuangan, sedangkan kinerja lingkungan dan kinerja sosial berpengaruh negatif tidak signifikan terhadap kinerja keuangan (Simbolon dan Sueb 2016). Sujana, Yuniarta, dan Karyawati (2017) berpendapat bahwa dimensi ekonomi, sosial, dan lingkungan tidak berpengaruh signifikan terhadap ROA. Kinerja ekonomi, kinerja sosial, dan kinerja lingkungan tidak berpengaruh pada kinerja keuangan (ROA) (Sejati dan Prastiwi, 2015).

Penelitian terdahulu telah mengungkapkan pengaruh sustainability reporting terhadap kinerja keuangan perusahaan dan ditemukan ketidakkonsistenan hasil penelitian, maka penelitian ini dilakukan dengan menganalisis pengaruh sustainability reporting terhadap perhitungan kinerja keuangan yang berfokus pada perusahaan manufaktur dan Jasa terdaftar di BEI. Tidak hanya itu penelitian ini berbeda dengan penelitian yang sebelumnya karena menggunakan $\mathrm{t}+1$ untuk melihat pengaruh sustainability reporting terhadap kinerja keuangan ditahun yang akan datang. Objek dari penelitian ini perusahaan manufaktur dan jasa. Perusahaan manufaktur merupakan perusahaan yang aktivitasnya mengolah bahan baku atau mentah menjadi barang jadi kemudian menghasilkan produk untuk dijual kepada konsumen. Aktivitas perusahaan manufaktur tersebut pasti tidak terlepas dari pembuangan limbah yang terkait dengan sustainability reporiting. Sedangkang perusahaan jasa perusahaan yang memberikan pelayanan terhadap konsumen. Aktivitas-aktivitas perusahaan jasa tidak terlepas dari indikator tentang pencemaran lingkungan yang berkaitan dengan sustainability reporting. Sebagai contoh perusahaan PT. Total Bangunan Persada yang memberikan jasa kontruksi akan memberikan dampak terhadap lingkungan sehingga perusahaan tersebut memerlukan pengungkapan sustainability reporting. Perhitungan kinerja keuangan menggunakan rasio Return On Asset (ROA) karena ROA merupakan salah satu rasio yang mengukur efektivitas perusahaan dalam menghasilkan keuntungan serta memanfaatkan total aset yang dimilikinya. ROA dikenal sebagai variabel untuk mengukur kinerja ekonomi (Dincer, 2011). ROA juga lebih terkait dengan efisiensi dibandingkan dengan Return On Equity (ROE) (Lorenzo et al,. 2009). Periode waktu menggunakan data terbaru selama tiga tahun dari tahun 2015 sampai 2017.

Persoalan dalam penelitian ini adalah bagaimana pengaruh sustainability reporting aspek ekonomi, lingkungan, dan sosial terhadap kinerja keuangan perusahaan manufaktur? Tujuan dari penelitian ini adalah untuk mengetahui pengaruh sustainability reporting aspek ekonomi, lingkungan, dan sosial terhadap kinerja keuangan perusahaan manufaktur dan Jasa. Penelitian ini diharapkan dapat bermanfaat 1). Bagi perusahaan sebagai bahan pertimbangan agar lebih memperhatikan dan melaksanakan program pengungkapan sustainability reporting. 2) Bagi calon investor sebagai pertimbangan pengambilan keputasan untuk melihat kinerja keuangan dengan adanya sustainability reporting.

\section{Metode}

Jenis penelitian yang digunakan adalah penelitian deskriptif kuantitatif. Data yang digunakan data sekunder (laporan berkelanjutan) berupa laporan keuangan yang didapatkan dari Bursa Efek Indonesia dan laporan sustainability reporting dari website perusahaan. Populasi dalam penelitian ini adalah seluruh perusahaan-perusahan manufaktur dan Jasa terdaftar di Bursa Efek Indonesia (BEI) menggunakan data waktu terbaru pada tahun 2015-2017.

Teknik pemilihan sampel yang dipakai adalah purposive sampling dengan kriteria tertentu. Kriteria tersebut meliputi: 1). Perusahaan mempublikasikan annual report lengkap selama tahun 2015-2017, 2). Mempublikasikan sustainability reporting atau mengungkapkan tanggung jawab sosial lainnya di tahun 2014-2016 berdasarkan Global Reporting Initiative (GRI) G4 Guidelines, 3). Memiliki data yang lengkap terkait dengan variabel-variabel yang digunakan dalam penelitian.

\section{Hasil dan pembahasan}

Hasil dari seleksi teknik purposive sampling diperoleh 30 sampel dari 10 perusahaan selama 3 tahun pengamatan. Berikut sample penelitian yang digunakan pada Tabel 1.

Tabel 1. Kriteria Pemilihan Sample

\begin{tabular}{lc}
\hline \multicolumn{1}{c}{ Keterangan } & Jumlah \\
\hline Perusahaan Manufaktur dan Jasa yang terdaftar di Bursa Efek Indonesia 2015-2017 & 356 \\
Perusahaan yang tidak menerbitkan Sustainability Reporting & $(340)$ \\
Perusahaan yang memiliki data tidak lengkap & $(6)$ \\
Perusahaan yang dijadikan sampel & 10 \\
Total sample selama 3 tahun & 30 \\
\hline
\end{tabular}


Tabel 2. Statis Deskriptif

\begin{tabular}{lcccc}
\hline & N & Minimum & Maximum & Mean \\
\hline ROA & 30 & 0,0386 & 0,6443 & 0,140406 \\
Kinerja Ekonomi & 30 & 0,2222 & 1,0000 & 0,574074 \\
Kinerja Lingkungan & 30 & 0,1667 & 1,0000 & 0,377002 \\
Kinerja Sosial & 30 & 0,0833 & 1,0000 & 0,395833 \\
Valid (listwise) & 30 & & & \\
\hline
\end{tabular}

( Sumber : Data diolah dengan SPSS versi 24)

Variabel dependen ROA dari perusahaan sampel pada tahun 2015-2017 diperoleh rata-rata sebesar 0,140406. Nilai terendah adalah sebesar 0,0386 yaitu PT Wijaya Karya Beton pada tahun 2015 sedangkan nilai tertinggi sebesar 0,6443 yaitu PT Indocement pada tahun 2017. Selanjutnya untuk Varibel Independen sampel yang digunakan pada tahun 2014-2016, pertama kinerja ekonomi nilai rata-rata sebesar 0,574074, nilai terendah 0,2222 pada tahun 2015 yaitu pada Unilever, serta pada tahun 2016 yaitu PT Indocement, PT Gas Negara, PT Wijaya Karya Beton, Unilever. Kemudian, nilai tertinggi kinerja ekonomi sebesar 1 yaitu PT AKR Corporindo pada tahun 2014 dan 2016. Kedua, Kinerja Lingkungan nilai rata-rata sebesar 0,377002, nilai terendah 0,1667 yaitu United Tractors pada tahun 2016 dan tertinggi 1 yaitu PT AKR Corporindo pada tahun 2015. Ketiga, Kinerja Sosial nilai rata-rata sebesar 0,395833, nilai terendah 0,0833 yaitu PT Indocement 2017 dan nilai tertinggi 1 PT AKR Corporindo pada tahun 2014 dan 2015.

Tabel 3. Hasil Uji Normalitas

\begin{tabular}{llll}
\hline & \multicolumn{3}{l}{ Kolmogorov-Sminov } \\
\hline & Statistic & Df & Sig. \\
\hline Unstandardized Residual & 0,079 & 30 & $0,200^{*}$ \\
\hline & & & (Sumber : Data diolah dengan SPSS versi 24)
\end{tabular}

Dari hasil uji normalitas di atas, dihasilkan sig. sebesar 0,2. Maka, dapat disimpulkan bahwa data dalam model regresi ini memiliki distribusi normal karena sig. lebih besar dari 0,05.

Tabel 4. Hasil Uji Multikolineraritas

\begin{tabular}{lccc}
\hline \multicolumn{1}{c}{ Variabel } & Tolerance & VIF & Kriteria \\
\hline Kinerja Ekonomi & 0,493 & 2,279 & Tidak Terjadi Multikolinearitas \\
Kinerja Lingkungan & 0,594 & 1,685 & Tidak Terjadi Multikolinearitas \\
Kinerja Sosial & 0,459 & 2,179 & Tidak Terjadi Multikolinearitas \\
\hline & & & (Sumber : Data diolah dengan SPSS versi 24)
\end{tabular}

Dari hasil uji multikolinearitas pada 3 model regresi pada tabel di atas, didapatkan nilai tolerance seluruh variabel independen lebih besar dari 0,10 dan nilai VIF seluruh variabel independen lebih besar dari 10. Hasil tersebut menyatakan bahwa dalam ketiga model regresi ini tidak terjadi masalah multikolinearitas dan dapat digunakan untuk analisis selanjutnya.

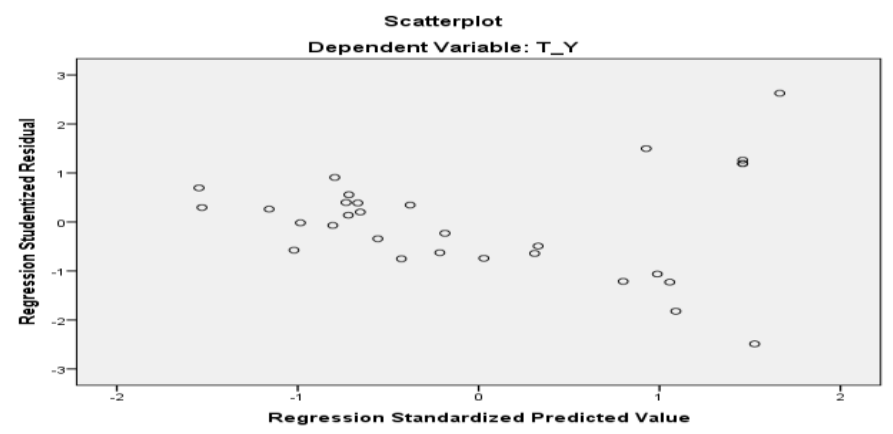

(Sumber : Data diolah dengan SPSS versi 24)

Gambar 1. Hasil Uji Heteroskedastisitas 
Gambar di atas menyimpulkan bahwa data dalam penelitian ini menunjukan ketiga model regresi yang akan digunakan tidak terdapat gejala heteroskedastisitas. Karena dapat dilihat titik-titik menyebar secara acak dan tidak membentuk pola tertentu.

Tabel 5. Hasil Uji Autokorelasi

\begin{tabular}{ccccccccc}
\hline $\mathbf{K}$ & $\mathbf{N}$ & $\mathbf{D}$ & $\mathbf{d L}$ & $\mathbf{d U}$ & $\mathbf{4 - d U}$ & 4-dL & DW & Kesimpulan \\
\hline 3 & 30 & 1,852 & 1,2138 & 1,6498 & 2,3502 & 2,7862 & 2,242 & $\begin{array}{c}\text { Tidak Terjadi } \\
\text { Autokorelasi }\end{array}$ \\
\hline
\end{tabular}

(Sumber : Data diolah dengan SPSS versi 24)

Pada ketentuan Durbi Watson, data dikatakan terhindar dari autokorelasi jika nilai Durbin Watson berada diantara d sampai dengan 4-dU. Dengan jumlah sample 30 dan 3 variabel independen maka diperoleh nilai tabel $d=1,852$ dan $4-d U=2,3502$. Nilai DW hasil perhitungan seperti yang ditunjukkan pada tabel di atas yaitu 2,242. Sehingga penelitian ini terbebas dari autokorelasi, karena $1,6498<1,852<2,242$.

Tabel 6. Hasil Uji Simultan (Uji F)

Pengujiaan dilakukan dengan menggunakan significance level $0.005(\alpha=5 \%)$.

\begin{tabular}{lllllll}
\hline & \multicolumn{1}{c}{ Model } & $\begin{array}{c}\text { Sum of } \\
\text { Squares }\end{array}$ & Df & $\begin{array}{c}\text { Mean } \\
\text { Square }\end{array}$ & F & Sig. \\
\hline \multirow{3}{*}{1} & Regression & 0,169 & 3 & 0,056 & 3,019 & $0,048^{\mathrm{b}}$ \\
& Residual & 0,484 & 26 & 0,019 & & \\
& Total & 0,652 & 29 & & & \\
\hline
\end{tabular}

(Sumber : Data diolah dengan SPSS versi 24)

Tabel uji F di atas diperoleh nilai signifikan 0,048 memiliki arti lebih kecil dari nilai ROA yaitu 0,05. Pada hasil uji F menghasilkan tingkat signifikan sebesar 0,048 maka dapat disimpulkan bahwa secara simultan Kinerja Ekonomi, Kinerja Lingkungan, dan Kinerja Sosial berpengaruh positif signifikan terhadap Kinerja Keuangan.

Metode yang dipakai pada penelitian ini adalah model persamaan analis regresi berganda untuk menguji adanya pengaruh variabel independen dan variabel dependen. Hubungan variabel dapat dilihat dari tabel berikut:

Tabel 7. Hasil Uji Analisis Linier Berganda

\begin{tabular}{lccc}
\hline \multicolumn{1}{c}{ Variabel } & B & T & Signifikasi \\
\hline (Constant) & 0,651 & 5,612 & 0,000 \\
Kinerja Ekonomi & $-0,375$ & $-1,715$ & 0,098 \\
Kinerja Lingkungan & 0,082 & 0,399 & 0,693 \\
Kinerja Sosial & $-0,131$ & $-0,625$ & 0,537 \\
\hline
\end{tabular}

(Sumber : Data diolah dengan SPSS versi 24)

Berdasarkan hasil perhitungan dan pengolahan tabel di atas maka, persamaan regresi liner berganda dari pengaruh variabel independen Kinerja Ekonomi, Kinerja Lingkungan, dan Kinerja Sosial terhadap Kinerja Keuangan adalah : Y+1 =0,651-0,375 $\mathbf{X}_{\mathbf{1}}+\mathbf{0 , 0 8 2} \mathbf{X}_{\mathbf{2}}-\mathbf{0 , 1 3 1} \mathbf{X}_{\mathbf{3}}+\mathbf{e}$.

Pengujian dilakukan dengan menggunakan significance level 0,05 $(\alpha=5 \%)$

Tabel 8. Hasil Uji Parsial (Uji t)

\begin{tabular}{cccc}
\hline Variabel & B & T & Signifikasi \\
\hline (Constant) & 0,651 & 5,612 & 0,000 \\
Kinerja Ekonomi & $-0,375$ & $-1,715$ & 0,098 \\
Kinerja Lingkungan & 0,082 & 0,399 & 0,693 \\
\hline
\end{tabular}


Berdasarkan hasil pengujian koefisien kinerja ekonomi terhadap kinerja keuangan (ROA) menunjukkan nilai signifikasi 0,098. Pada tingkat $\alpha=5 \%$ maka koefisien regresi tersebut tidak signifikan karena 0,098 > 0,05 sehingga disimpulkan bahwa kinerja ekonomi tidak berpengaruh terhadap kinerja keuangan perusahaan.

Berdasarkan hasil pengujian koefisien kinerja lingkungan terhadap kinerja keuangan (ROA) menunjukkan besarnya 0,693 . Pada tingkat $\alpha=5 \%$ maka koefisien regresi tersebut tidak signifikan karena $0,693>0,05$ sehingga disimpulkan bahwa lingkungan tidak berpengaruh terhadap kinerja keuangan perusahaan.

Berdasarkan hasil pengujian koefisien kinerja sosial terhadap kinerja keuangan (ROA) menunjukkan besarnya nilai signifikasi 0,537 . Pada tingkat $\alpha=5 \%$ maka koefisien regresi tersebut tidak signifikan karena 0,537 > 0,05 sehingga disimpulkan bahwa kinerja sosial tidak berpengaruh terhadap kinerja keuangan perusahaan.

Tabel 9. Hasil Uji Koefisien Detiminasi

\begin{tabular}{cccc}
\hline Model & R & R Square & Adjusted R Square \\
\hline 1 & $0508^{\mathrm{a}}$ & 0,258 & 0,173 \\
\hline & & (Sumber : Data diolah dengan SPSS versi 24)
\end{tabular}

Tabel diatas menunjukan nilai Adjusted $R$ Square sebesar 0,173. Hal ini, dapat diartikan pengungkapan Sustainability Reporting perusahaan manufaktur dan jasa yang terdaftar di BEI 2014-2016 dapat dijelaskan oleh variabel bebas yaitu kinerja ekonomi, kinerja sosial dan kinerja lingkungan sebesar $17,3 \%$ dan sisanya $82,7 \%$ ditentukan oleh variabel lain yang tidak dianalisis dalam penelitian ini.

Hasil uji pengungkapan kinerja ekonomi tidak berpengaruh terhadap kinerja keuangan perusahaan. Bisa jadi jangka waktu yang digunakan relatif pendek dan juga banyak item - item tidak diungkapakan bepengaruh terhadap kinerja keuangan. Adams (2010) dalam Nofianto dan Agustina (2014) mengatakan bahwa sustainability reporting akan memiliki pengaruh yang signifikan pada kurun waktu yang panjang. Hal ini sesuai dengan penelitian Burhan dan Rahmanti (2009) yang memaparkan dalam penelitiannya bahwa pengungkapan kinerja ekonomi tidak memiliki pengaruh terhadap kinerja keuangan karena penelitian tersebut menggunakan kurun waktu yang pendek. Hasil penelitian ini juga sejalan dengan hasil penelitian Nofianto dan Agustina (2014) menyatakan bahwa kinerja ekonomi perusahaan tidak berpengaruh signifikan terhadap kinerja keuangan karena penelitian dilakukan dalam jangka pendek. Kemudian, juga didukung oleh penelitian, Burhan dan Rahmanti (2012), Taringa dan Samuel (2014), Sujana, Yuniarta, Karyawati (2017), dan Sejati dan Prastiwi (2015) bependapat bahwa kinerja ekonomi tidak berpengaruh terhadap kinerja keuangan.

Pada pengungkapan kinerja lingkungan menunjukkan tidak berpengaruh terhadap kinerja keuangan. Kinerja lingkungan mengungkapkan informasi berupa isu-isu lingkungan yang berkaitan dengan masyarakat sekitar perusahaan. Biasanya, sustainabilty reporting dalam pengungkapan kinerja lingkungan akan berpengaruh pada nilai perusahaan maupun respon pasar. Dalam pengungkapannya diperkirakan, stakeholder tidak cenderung melihat sustainability reporting namun lebih cenderung melihat annual reporting (laporan tahunan) yang mana lebih melihat tingkat respon pasar yang baik. Sama dengan penelitian sebelumnya, Nofianto dan Agustina (2014) memaparkan bahwa pengungkapan kinerja lingkungan tidak memberikan pengaruh pada kinerja keuangan. Tidak hanya itu Burhan dan Rahmanti (2012), Simbolon dan Sueb (2016), Sujana, Yuniarta, Karyawati (2018), serta Sejati dan Prastiwi (2015) juga berpendapat bahwa kinerja lingkungan tidak berpengaruh terhadap kinerja keuangan perusahaan.

Hasil uji pengungkapan kinerja sosial menunjukkan tidak berpengaruh terhadap kinerja keuangan perusahaan yang diukur menggunakan ROA. Besar kecilnya ROA dipengaruhi oleh tingkat penjualan. Di sisi lain tingkat penjualan juga tidak memberikan dampak pada pengungkapan sustainability reporting karena stakeholder tidak memiliki kaitan dengan kegiatan penjualan kepada konsumen. Menurut Bukhori dan Shopia (2017) pengungkapan kinerja sosial akan memberikan pengaruh pada nilai perusahaan dengan market respon yang baik dan akan berpengaruh pada kinerja keuangan. Proses kinerja sosial jangka pendek tersebut tidak berpengaruh pada kinerja keuangan namun proses kinerja jangka panjang yang memberikan pengaruh. Hal tersebut didukung oleh penelitian Adhima (2012), Simbolon dan Sueb (2016), dan Nofianto dan Agustina (2014) yang menyatakan kinerja sosial tidak berpengaruh terhadap kinerja keuangan perusahaan. Sujana, Yuniarta, Karyawati (2017) serta Sejati dan Prastiwi (2015) juga 
berpendapat bahwa kinerja sosial tidak memiliki pengaruh terhadap kinerja keuangan perusahaan. Sedangkan hasil penelitian ini betentangan dengan temuan Wijayanti (2014) dan Burhan dan Rahmanti (2009) yang menyatakan kinerja sosial berpengaruh postif terhadap kinerja keuangan perusahaan.

\section{Simpulan dan saran}

Berdasarkan hasil pengujian dan pembahasan di atas dapat disimpulkan secara parsial semua dimensi sustainability reporting yaitu kinerja ekonomi, kinerja lingkungan, dan kinerja sosial tidak berpengaruh terhadap kineja keuangan (ROA). Jika sustainability reporting diteliti dalam jangka pendek tidak akan menimbulkan pengaruh terhadap kinerja keuangan perusahaan. Pada penelitian ini, memiliki beberapa keterbatasan yaitu jumlah sampel yang sedikit yaitu 10 perusahaan selama 3 tahun, rentang tahun dalam penelitian ini pendek hanya 3 tahun, dan kurangnya perusahaan yang mengeluarkan laporan sustainability reporting.

Perusahaan diharapkan menerbikan sustainability report dengan lengkap agar stakeholder tertarik menjadikan sustainability report sebagai bahan pertimbangan untuk berinvestasi. Kemudian bagi stakeholder, agar tidak hanya melihat laporan keuangan saja dalam berinvestasi, namun juga melihat sustainability report yang di dalamnya terdapat laporan kinerja ekonomi, kinerja lingkungan, dan kinerja sosial perusahaan. Penelitian ini masih bersifat eksploratif sehingga masih terbuka untuk diteliti kembali, untuk penelitian selanjutnya diharapkan dapat mengambil rentang waktu yang lebih lama minimal 5 tahun sebagai objek pada penelitian agar bisa mendapat hasil yang lebih akurat.

\section{Daftar Rujukan}

ACCA. (2013). The Business Benefits of Sustainability Reporting. Singapore.

Adhima, M.F. 2012."Pengaruh Penfungkapan Sustainability Reporting Terhadap Profitabilitas Perusahaan. Studi Kasus pada Perusahaan Mnufaktur yang Terdaftar dalam Bursa Efek Indonesia". Skripsi dipublikasikan. Universitas Brawijaya.

Badan Pengawas Pasar Modal dan Lembaga Keuanga 2012. Peraturan Bapepam-LK nomer X.K.6. http//www.ojk.go.id/id/regulasi/Pages/BAPEPAM-XK6-tentang-Penyampaian-Laporan-TahunanEmiten-atau-Perusahaan-Publik.aspx.

Bukhori, M. R. T., \& Shopia, D. (2017). Pengaruh Pengungkapan Sustainability Report Terhadap Kinerja Keuangan. Sikap, 2(1), 14.

Burhan, A. H. N., \& Rahmanti, W. (2012). The Impact of Sustainability Reporting on Company Performance. Journal of Economics, Business, and Accountancy Ventura, 15(2), 16.

Dincer, B. (2011). Do the Shareholders Really Care about Corporate Social Responsibility?. International Journal of Business and Social Science, 10(2), 6.

Eduardus, E., \& Juniarti. (2016). Kinerja Sosial Perusahaan dan Kinerja Keuangan Perusahaan yang Diukur Menggunakan Tobin'sq. Business Accounting Review, 4(1), 12.

Elkington, J. (1997) Canibals with Forks: The Triple Bottom Line of 21 ${ }^{\text {st }}$ Century. Business Oxfoard: Capstone Publishing Lnt.

Global Reporting Initiative.2012. Sustainability Reporting Guidelines. Version 4.

Harsanti, P., Robiyanto, F., \& Mu'anaqoh, S. (2014). Pengujian Silmutan Kinerja Lingkungan, Corporate Social Responsibility Disclosure dan Kinerja Keuangan dalam Prespektif Teori Legitimasi. 11.

Ikatan Akuntan Indonesia. 2007. Standart Akuntansi Keuangan. Jakarta: Salemba Empat.

Ikatan Akuntan Indonesia. 2009. Standar Akuntansi Keuangan, PSAK No.1: Laporan Keuangan. Jakarta: Salemba Empat 
Karyawati, N.N.A., Yuniarta, A.G., \& Sujana, E. (2017). Pengaruh Pengungkapan Lapora Keberkelanjutan Terhadap Kinerja Keuangan Perusahaan (Studi Empiris Pada Perusahaan Non-Keuangan yang Terdaftar di Bursa Efek Indonesia Periode 2013-2015). Jurnal Akuntasi Program S1, 7 (1), 10.

KPMG. (2008). The KPMG Survey of Corporate Responsibility Reporting 2008. Amstelveen: KPMG.

Lesmana, Y., \& Tarigan, J. (2014). Pengaruh Sustainability Reporting Terhadap Kinerka Keuangan Perusahaan dari Sisi Asset Management Ratios. Business Accounting Review, 2(1), 10.

Lorenzo, J.M.P., Luis, R.D., Isabel, G.A.,\& Isabel, M.G.S. (2009). Factor Influencing the Disclousure of Greenhouse Gas Emisoins in Companies Word Wide. Management Decision, 47(7), 16.

Masyitah, E. (2016). Faktor-Faktor yang Mempengaruhi Pengungkapan Sosial (Social Disclousure) dalam Laporan Keuangan Tahunan Perusahaan Manufaktur yang Terdaftar di Bursa Efek Indonesia. Jurnal Al-Qasd, 1(1), 19.

Natalia, O., \& Wahidahwati. (2016). Faktor-Faktor yang Mempengaruhi Tingkat Pengungkapan Sustainability Report. Jurnal Ilmu dan Riset Akuntansi, 5(11), 11.

Natalia, R., \& Tarigan, J. (2014). Pengaruh Sustainability Reporting Terhadap Kinerja Keuangan Perusahaan Publik dari Sisi Profatibility Ratio. Business Accounting Review, 2(1), 10.

Nofianto, E., \& Agustina, L. (2014). Analisis Pengaruh Sustainability Report Terhadap Kinerja Keuangan Perusahaan. Accounting Analysis Journal, 3(3), 9.

Nurhayati. (2014). Analisis Pengaruh Kinerja Keuangan Terhadap Pelaporan Berkelanjutan (Sustainability Reporting) pada Perusahaan Logam dan Kimia yang Listing di BEI. Jurnal Audit dan Akuntasi Fakultas Ekonomi Universitas Tanjungpura, 3(1), 30.

Pratiwi, R. D., \& Sumaryati, A. (2014). Dampak Sustainability Reporting Terhadap Kineja Keuangan dan Risiko Perusahaan. Jurnal Dinamika Akuntasi, 6(2), 15.

Putusan Mahkamah Konstitusi Republik Indonesia Nomer 53/PUU-VI/2008 tentang judicial review Nomer 40 Tahun 2007 tentang Perseroan Terbatas.

Rahmani, A., \& Andayani. (2013). Pengaruh Corporate Social Responsibility Terhadap Kinerja Perusahaan. Jurnal Ilmu \& Riset Akuntansi, 2(4).

Retnosari. (2018). Pengaruh Dimensi Sustainability Reporting Terhadap Kinerja Keungan Pada Perusahaan yang Terdaftar di Bursa Malaysia. Jurnal Ilmiah Akuntansi dan Keuangan, 7(01), 13.

Ross, S., Westerfield, R \& Jordan, B. (2003). Fundamental of Corporate Finance, Sixth Edition, Singapore: McGraw-Hill Book Company.

Safitri, D. A., \& Fidiana. (2015). Sustainability Report Terhadap Kinerja Keuangan dan Pasar. Jurnal Ilmu dan Riset Akuntansi, 4(4), 15.

Sari, M. P. Y., \& Marsono. (2013). Pengaruh Kinerja Keuangan, Ukuran Perusahaan dan Corporate Governance Terhadap Pengungkapan Sustainability Report. Diponegoro Journal of Accounting, 2(3), 10.

Sari, N. A., Artinah, B., \& Safriansyah. (2017). Sustainability Report dan Nilai Perusahaan di Bursa Efek Indonesia. SPREADE, 7(1), 10.

Sejati, B. P., \& Prastiwi, A. (2015). Pengaruh Pengungkapan Sustainability Report Terhadap Kinerja dan Nilai Perusahaan. Diponegoro Journal Of Accounting, 4(1), 12.

Soelistyoningrum, J. N., \& Prastiwi, A. (2011). Pengaruh Pengungkapan Sustainability Report Terhadap Kinerja Keuangan. 29. 
Simbolon, J., \& Sueb, M. (2016). Pengaruh Pengungkapan Sustainability Report Terhadap Kinerja Keuangan Perusahaan (Studi Empiris pada Perusahaan Tambang dan Infrastruktur Subsektor Energi yang Terdaftar di BEI 2010-2014). Simposium Nasional Akuntansi XIX, 30.

Tarigan, J., \& Samuel, H. (2014). Pengungkapan Sustainability Report dan Kinerja Keuangan. Akuntansi dan Keuangan, 16(2), 14. doi: 10.9744/jak.16.2.88-101.

Wijaya, E., \& Sumiati, N. (2017). The Effect of The Financial Performance, Firm Size and The Disclousere of Corporate Social Responsibility of The Firm Value At Manufacturing Companies In 2013-2015 Periods In Indonesia Stock Exchange. 1(3), 12.

Wijayanti, R. (2016). Pengaruh Sustainability Report Terhadap Kinerja Keuangan Perusahaan. 13.

Yunitasari, R. (2017). Dampak Laporan Berkelanjutan Terhadap Kinerja Keuangan Perusahaan di BEI Tahun 2011-2015. 